\title{
Modeling Study on Heat Transfer in Marangoni Dropwise Condensation for Ethanol-Water Mixture Vapors
}

\author{
Jinshi Wang ${ }^{1, * \mathbb{C}}$, Ziqiang Ma ${ }^{1}$, Yong $\mathrm{Li}^{2}$, Weiqi Liu ${ }^{1}$ and Gen $\mathrm{Li}^{1}$ \\ 1 State Key Laboratory of Multiphase Flow in Power Engineering, Xi'an Jiaotong University, \\ Xi'an 710049, China; mzq931001@stu.xjtu.edu.cn (Z.M.); liuweiqi1995@stu.xjtu.edu.cn (W.L.); \\ gen.li@mail.xjtu.edu.cn (G.L.) \\ 2 Institute of Fundamental and Frontier Sciences, University of Electronic Science and Technology of China, \\ Chengdu 610054, China; liyong-ccsi@uestc.edu.cn \\ * Correspondence: wangjinshi@mail.xjtu.edu.cn; Tel.: +86-29-82665408
}

Received: 24 November 2020; Accepted: 17 December 2020; Published: 20 December 2020

\begin{abstract}
In this paper, a model was developed to predict the heat transfer characteristics of Marangoni dropwise condensation. In accordance with the feature of Marangoni condensation, condensation was treated as dropwise condensation of mixture vapors. The condensation space was divided into two parts: the vapor diffusion layer and the condensate layer. For the condensate layer, the classical heat transfer calculation method of dropwise condensation was imitated to obtain the heat transfer characteristics. For the vapor diffusion layer, the heat transfer characteristics were achieved by solving the conservation equations. These heat transfer characteristics were coupled through the conjunct boundary, which was the vapor-liquid interface. The model was applied to the condensation of water-ethanol mixture vapors. A comparison with the existing experimental data showed that the developed model could basically reflect the influences of vapor-to-surface temperature difference, vapor concentration, vapor pressure, and vapor velocity on heat transfer characteristic of Marangoni condensation. Results showed that some differences existed between the calculation results and experimental results, but the prediction deviation of the model could be acceptable in the range of vapor-to-surface temperature difference where the condensation heat transfer coefficients reached peak values.
\end{abstract}

Keywords: Marangoni condensation; dropwise condensation; heat transfer; model; ethanol-water mixture vapors

\section{Introduction}

The condensation process usually occurs in many industrial applications and is usually divided into filmwise condensation and dropwise condensation in accordance with the condensation modes. The heat transfer coefficients of dropwise condensation are much higher than those of filmwise condensation, which is why increasing attention has been paid to achieve dropwise condensation in recent years. A traditional method of promoting dropwise condensation is usually to change the hydrophily of the condensing surface by using coatings, surface structures, or adding chemical additives in vapors [1] However, the coatings or surface structures are easily damaged in the real industrial environment, and the additives are out of operation after a long time. Thus, surface condensers today are designed to operate in the filmwise condensation mode, although dropwise condensation could be maintained for a very long time in a laboratory environment [2].

In 1961, Mirkovich and Missen [3] first found that the condensation modes of mixture vapors changed from filmwise condensation to dropwise condensation. Later researchers found that 
this condensation of mixtures was caused by the Marangoni effect, which was driven by surface tension gradients on the condensate surface. This condensation phenomenon is named Marangoni condensation or pseudo-dropwise condensation, which is a new way to achieve dropwise condensation. It does not involve changing the hydrophily of the condensing surface. Due to the physical properties of the condensate, the dropwise condensation modes could last for a long time during condensation. The heat transfer characteristic of Marangoni condensation is very excellent, which can be applied in refrigeration systems, power generation systems, and so on. Therefore, some experimental investigations have been performed on heat transfer characteristics of Marangoni condensation [4-20]. Experimental results indicated that the thermal conduction resistance of the condensate could be significantly reduced, and the heat transfer could be significantly enhanced, despite a diffusion layer between the condensate and the main vapors, compared with the filmwise condensation of pure vapor. Therefore, the main influencing factors of heat transfer characteristics in Marangoni condensation, including vapor-to-surface temperature difference $[4,7,9,10,13,15,20]$, vapor concentration $[5-10,13-16,19,20]$, vapor pressure $[10,13,17,19]$, vapor velocity $[7,9-11,13,17,20]$, and tube diameter $[12,18]$ were widely studied.

Several researchers found that the additive could affect heat transfer characteristics. Sarafraz and Peyghambarzadeh [21] experimentally investigated the flow boiling heat transfer of water-diethylene glycol mixtures inside a vertical annulus influence at different parameters. The heat transfer coefficient improved slightly when a small amount of diethylene glycol was added to the mixture. Yang et al. [22] presented the effects of heat fluxes, concentrations of glycerol, and velocities with the water-glycerol mixtures in a microchannel heat exchanger. They found that the convective heat transfer coefficient of the water-glycerol mixtures was larger than that of water. An investigation of the contact angle can help to reveal the condensation mechanism. Sarafraz and Arjomandi [23] measured the contact angle between the gallium and the surface and obtained the heat transfer coefficient of a free surface liquid film flowing on the heating surface. The heat transfer coefficient increased with the increase in the contact angle of the liquid metal.

Although many experimental studies on Marangoni condensation have been published, little information is available on the theoretical investigation of Marangoni condensation. Theoretical analysis of Marangoni condensation was first conducted by Hijikata et al. [24] with perturbation theory. Results indicated that the drops that appeared in Marangoni condensation were generated by the instability of the condensate, and the condensation heat transfer coefficient was nearly equal to that of unsteady filmwise condensation. Akiyama et al. [25] numerically investigated the condensation process of ethanol-water mixture vapors on a two-dimensional horizontal rectangular area. The formation process of the drops was simulated. Results indicated that the calculated condensation heat transfer coefficient was slightly higher than that of smooth filmwise condensation and much lower than that of dropwise condensation of pure vapor. Utaka and Wang [7] analyzed the thermal resistance of the vapor diffusion layer during the condensation of ethanol-water mixtures. They found that, for the process of the condensing surface just after sweeping by a departing drop in a typical condensation process, the thickness of the vapor diffusion layer became thicker with the increase in time, and the thermal resistance became larger with the increase in ethanol vapor concentration. Vemuri et al. [8] presented a theoretical model to predict the condensation heat transfer characteristic of steam with additives on horizontal tubes. The surface tension gradient on condensation heat transfer was considered, and the condensation mode was treated as filmwise condensation. The calculation results agreed well with the experimental data. By applying long-wave approximation, Kanatani [26] studied the instability of the condensate film in a binary vapor mixture system and found that the effect of temperature on condensation transfer coefficient could not be neglected in the condensation of a water-ethanol system. Later, by employing the asymptotic analysis for large wavenumbers, Kanatani $[27,28]$ numerically calculated the critical thickness, the mean mass flux, and wavelength for the water-ethanol system. $\mathrm{Li}$ et al. [29] proposed a semi-theoretical model to predict the condensation heat transfer characteristic of ethanol-water mixtures. In this model, the liquid-vapor interface temperature was assumed as 
the same as that in filmwise condensation of binary vapor presented by Sparrow and Marschall [30], and the condensation heat transfer was obtained by using the investigation method of dropwise condensation for pure vapor. The general trend of the experimental data was well predicted by this model. Wang et al. [31] introduced several dimensionless numbers to represent the heat transfer results and essential influencing factors of Marangoni condensation. They developed a heat transfer correlation of Marangoni condensation for water-ethanol mixture, and the deviation between the experimental results and the prediction results ranged from $-25 \%$ to $30 \%$. Zhou et al. [32] considered that the dimensionless numbers represented the Marangoni condensation effects and developed heat transfer correlations for water-ethanol vapor mixture condensation in a plate heat exchanger, with a deviation from $-3.2 \%$ to $7.9 \%$.

The detailed condensation mechanism and microscopic understanding still need to be further investigated because of the complexity of Marangoni condensation. Furthermore, theoretical studies on Marangoni condensation are still limited, and no systematic theory and mathematical models have been presented to predict the heat transfer characteristic quantitatively and accurately. The purpose of this paper is to develop a theoretical model to predict the heat transfer characteristics of Marangoni dropwise condensation, especially for the condensation of water-ethanol mixture vapors. The model in this paper will be used in obtaining the heat transfer coefficients of water-ethanol mixtures, and establishing the relationship between the heat transfer characteristics and condensation modes. Moreover, this model will reveal the mechanism of Marangoni condensation and help to control the heat transfer characteristics by active regulation. Furthermore, the presented model gives a more fundamental description of the mechanism for Marangoni dropwise condensation, which can be used to guide the selection of the operating conditions and the design of compact condensers to enhance heat transfer.

\section{Physical Model of Marangoni Dropwise Condensation}

Marangoni condensation is a condensation process of mixture vapors. The schematic diagram of Marangoni condensation on a vertical plate is shown in Figure 1. The condensate layer and the vapor diffusion layer are located between the condensing surface and main vapors. The condensate layer is non-filmwise, and a vapor diffusion layer exists in Marangoni condensation. However, the condensation modes of Marangoni condensation are similar to the dropwise condensation of pure vapor on hydrophobic surfaces. According to the feature of Marangoni condensation, condensation can be treated as dropwise condensation of mixture vapors.

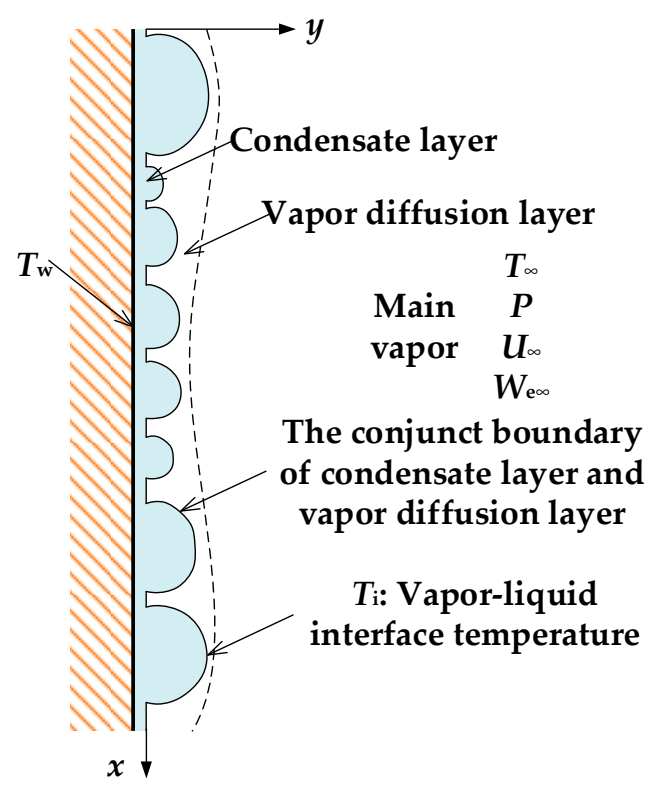

Figure 1. Schematic diagram of Marangoni condensation. 
For laminar filmwise condensation of a binary vapor, Sparrow and Marschall [30] presented a method to predict the heat transfer characteristics, in which the condensing surface was divided into the condensate film and the vapor boundary layer. The conservation equations were established for each part. These two parts had a conjunct boundary, which was the vapor-liquid interface. With the use of a similarity transformation method, the conservation equations were solved, and the heat transfer characteristics were obtained. Fujii [33] systematically investigated the forced-convection and free-convection condensation heat transfer of binary vapors. A similar approach was adopted by Sparrow and Marschall [30], who obtained the heat transfer characteristics by solving the conservation equations and coupling the conjunct boundary.

Therefore, the condensation region can be divided into the vapor diffusion layer and the condensate layer in Marangoni condensation, which is a comprehensible and suitable approach. Unlike in the filmwise condensation of binary vapors, a very thin film exists between the drops and the condensing surface, and many drops are found on the condensate layer in Marangoni condensation. The heat transfer characteristics of the condensate layer with drops could be obtained by using the classical heat transfer calculation method of dropwise condensation, and the heat transfer characteristics of the vapor diffusion layer could be achieved by solving the conservation equations. However, these two heat transfer characteristics should be coupled through the conjunct boundary, which is the vapor-liquid interface. To obtain the heat transfer characteristics of Marangoni condensation, several simplifications and assumptions are made as follows:

(1) The main vapor is saturated.

(2) The interface between the condensate layer and the vapor diffusion layer is saturated.

(3) The component concentration in the condensate liquid is uniform.

(4) The thin condensate film under the drops with a thickness of about $1 \mu \mathrm{m}$ is neglected.

(5) The effect of the movement drops on the gas diffusion layer is not included.

\section{Mathematical Model of Marangoni Dropwise Condensation}

\subsection{Heat Transfer through Condensate Drops}

In the existing heat transfer models for the dropwise condensation of pure vapor, the heat flux through a single drop is usually calculated first, and then the mean heat flux through the whole condensing surface is obtained by the integration of all drops on the surface. Finally, the mean condensation heat transfer coefficient is calculated. To calculate the heat transfer through condensate drops, two assumptions are made.

(1) The temperature of the condensing surface is uniform.

(2) The condensate drops are hemispherical and heat is transferred by conduction.

\subsubsection{Heat Transfer through Single Drop}

For a single drop, the total thermal resistance includes three parts: the thermal resistance caused by the drop curvature, the thermal resistance caused by the heat conduction, and the thermal resistance caused by the vapor-liquid interfacial resistance. The thermal resistances can also be presented as temperature differences, as shown in Equations (1)-(3), respectively.

The temperature difference due to the vapor-liquid interfacial curvature can be expressed as [34]:

$$
\Delta T_{\mathrm{c}}=\frac{2 T_{\mathrm{i}} \sigma_{\mathrm{L}}}{r h_{\mathrm{f} g} \rho_{\mathrm{L}}}
$$

where $h_{\mathrm{fg}}$ is the heat latent of the vapor, $\mathrm{J} \cdot \mathrm{kg}^{-1} ; \rho_{\mathrm{L}}$ is the density of the condensate, $\mathrm{kg} \cdot \mathrm{m}^{-3}$; $\sigma_{\mathrm{L}}$ is the surface tension of the condensate, $\mathrm{N} \cdot \mathrm{m}^{-1} ; T_{\mathrm{i}}$ is the top temperature of the drop and is also the liquid-vapor interface temperature, $\mathrm{K}$; and $r$ is the radius of the drop, $\mathrm{m}$; 
Heat conduction through a hemispherical drop is given by

$$
\Delta T_{\mathrm{d}}=\frac{q_{\mathrm{b}} r}{4 \pi r^{2} \lambda_{\mathrm{L}}}
$$

where $\lambda_{\mathrm{L}}$ is the thermal conductivity of the condensate, $\mathrm{W} \cdot \mathrm{m}^{-1} \cdot \mathrm{K}^{-1}$; and $q_{\mathrm{b}}$ is the heat transfer rate through the drop, $\mathrm{W}$.

Vapor-liquid interfacial resistance for a hemispherical drop is given by

$$
\Delta T_{\mathrm{i}}=\frac{q_{\mathrm{b}}}{2 \pi r^{2} h_{\mathrm{i}}}
$$

where $h_{\mathrm{i}}$ is the interfacial heat transfer coefficient [29].

The total temperature difference consists of three parts, which is equal to the temperature difference between the wall temperature and the top temperature of the drop, which is presented as:

$$
\Delta T_{\mathrm{L}}=\Delta T_{\mathrm{c}}+\Delta T_{\mathrm{d}}+\Delta T_{\mathrm{i}}
$$

where $\Delta T_{\mathrm{C}}$ is the temperature difference due to the vapor-liquid interfacial curvature, $\mathrm{K} ; \Delta T_{\mathrm{d}}$ is the temperature difference due to the vapor-liquid interfacial resistance, $\mathrm{K} ; \Delta T_{\mathrm{i}}$ is the temperature difference due to the drop conduction resistance, $\mathrm{K}$; and $\Delta T_{\mathrm{L}}$ is the sum of the above three temperature differences, $\mathrm{K}$.

Thus, the heat transfer rate through a single drop is presented as

$$
q_{\mathrm{b}}=\frac{4 \pi r^{2}\left(\Delta T_{\mathrm{L}}-\frac{2 \sigma_{\mathrm{L}} T_{\mathrm{i}}}{r \rho_{\mathrm{L}} h_{\mathrm{fg}}}\right)}{\frac{r}{\lambda_{\mathrm{L}}}+\frac{2}{h_{\mathrm{i}}}}
$$

To calculate the mean heat flux through the whole condensing surface, the drop size distribution, the maximum drop size, and the minimum drop size should be known.

\subsubsection{The Drop Size Distribution}

Although dropwise condensation is a dynamic process, and the drop distribution on the surface seems to be random, many researchers demonstrated that the whole drop size distribution follows a certain distribution function. Le Fever and Rose [34] proposed a drop size distribution function for the dropwise condensation of pure vapor:

$$
\gamma=1-\left(\frac{r}{r_{\max }}\right)^{1 / 3}
$$

Or

$$
N(r) d r=\frac{1}{3 \pi r^{2}}\left(\frac{r}{r_{\max }}\right)^{-2 / 3} \frac{d r}{r_{\max }}
$$

where $r_{\max }$ is the maximum drop radius, $\mathrm{m}$; and $\gamma$ is the fraction of surface area covered by drops with a radius larger than $r$. Equation (7) denotes the fraction of the surface area covered by drops in the size range $[r, r+d r]$.

Equation (6) or Equation (7) agrees well with many experimental data, which are based on both experimental data and theoretical derivation. Although the mechanism of Marangoni condensation is different from that of the dropwise condensation of pure vapor, they are similar in condensation modes from a macro perspective. In Ref. [29], Li et al. compared the drop size distribution of the Marangoni condensation for water-ethanol mixture vapors with the results calculated by Equation (7), and they found that these results were close to each other when the condensation modes were pseudo-dropwise 
condensation. Therefore, in this paper, Equation (7) is adopted to calculate the drop size distribution for Marangoni condensation of water-ethanol mixture vapors.

\subsubsection{The Maximum Drop Radius}

Rose [35] presented an empirical formula of the maximum drop radius for the dropwise condensation of pure steam, which is shown in Equation (8). For the Marangoni condensation of water-ethanol mixture vapors, the maximum drop radius depends on the vapor-to-surface temperature difference and ethanol vapor concentration. Li et al. [29] measured the maximum drop radius over a wide range of ethanol vapor concentrations. They reported that the maximum drop radius increased nearly linearly with the increase in vapor-to-surface temperature difference, and the maximum drop radius increased monotonously with the increase in the ethanol vapor concentration at a certain vapor-to-surface temperature difference. The range of the maximum drop radius was from $1 \mathrm{~mm}$ to 7 $\mathrm{mm}$. In the present study, the maximum drop radius is determined based on the experimental data of Li et al. [29].

$$
r_{\max }=0.4\left(\frac{\sigma_{\mathrm{L}}}{\rho_{\mathrm{L} g}}\right)^{1 / 2}
$$

where $g$ is the gravitational acceleration, $\mathrm{m} \cdot \mathrm{s}^{-2}$.

\subsubsection{The Minimum Drop Radius}

Graham and Griffith [36] and Tanasawa and Shibata [37] reported that the minimum drop radius was about $0.07 \mu \mathrm{m}$ and $0.01 \mu \mathrm{m}$, respectively. Graham and Griffith [36] presented an equation based on thermodynamical analysis, as follows:

$$
r_{\min }=\frac{2 T_{\mathrm{i}} \sigma_{\mathrm{L}}}{h_{f g} \rho_{\mathrm{L}}\left(T_{\mathrm{i}}-T_{\mathrm{cs}}\right)}
$$

where $T_{\mathrm{cs}}$ is the condensing surface temperature, $\mathrm{K}$.

The measurement of the minimum drop radius is difficult due to the limitations of the measurement technique. Rose [35] reported that the calculation results of the condensation heat transfer coefficient agreed well with the experimental data when the minimum drop radius was 10 times the value calculated from Equation (9). For Marangoni condensation of binary mixtures, the measurement of the minimum drop radius is more difficult. Utaka et al. [38] measured the distance between the initial condensate drops during the condensation of water-ethanol mixture vapors. They found that the minimum drop radius of water-ethanol mixture vapors was much bigger than that of pure vapor. Later Utaka and Nishikawa $[39,40]$ used the laser extinction method to measure the thickness of the condensate layer. They confirmed that a thin liquid film was present under the drops. The thickness measured in the experiments was the sum of the thin liquid film and the drops on the liquid film. The total thickness was a dynamic value, and the minimum value was approximately $1 \mu \mathrm{m}$. The condensate drops were not strictly spherical during Marangoni condensation, therefore, making the distinction between the drops and the condensate film with waves is difficult. In other words, the condensate layer with $1 \mu \mathrm{m}$ height could be thought as drops with a $1 \mu \mathrm{m}$ radius. From this point of view, the minimum drop radius during Marangoni condensation of water-ethanol mixture vapors can be treated as $1 \mu \mathrm{m}$.

\subsubsection{Condensation Heat Flux and Heat Transfer Coefficient}

The mean heat flux through the entire condensing surface can be calculated by:

$$
q=\int_{r_{\min }}^{r_{\max }} q_{\mathrm{b}}(r) N(r) d r
$$


The condensation heat transfer coefficient can be calculated by:

$$
h=q /\left(T_{\infty}-T_{\mathrm{cs}}\right)
$$

where $T_{\infty}$ is the temperature of the main vapor, $\mathrm{K}$.

\subsection{Heat Transfer through the Vapor Diffusion Layer}

As shown in Figure 1, considering the flow direction and the heat conduction along the direction normal to the condensing surface, the heat conduction process is a two-dimensional, steady-state problem in the vapor diffusion layer. The flow direction is defined as $x$-direction, and the direction normal to the condensing surface is defined as $y$-direction. A detail that should be pointed out is that the origin of the $y$-direction is defined as the top of the condensate layer, which is the vapor-liquid interface, because the height of the condensate layer is non-uniform and random along the flow direction. For the vapor diffusion layer of Marangoni condensation, several conservation equations are required to describe the flow, heat transfer, and diffusion processes.

\subsubsection{Governing Equations}

The equations for the flow, heat, and mass, and energy process are as follows:

Continuity equation:

$$
\frac{\partial u_{\mathrm{V}}}{\partial x}+\frac{\partial v_{\mathrm{V}}}{\partial y}=0
$$

Momentum equation:

$$
u_{\mathrm{V}} \frac{\partial u_{\mathrm{V}}}{\partial x}+v_{\mathrm{V}} \frac{\partial u_{\mathrm{V}}}{\partial y}=-\frac{1}{\rho_{\mathrm{V}}} \frac{\partial P}{\partial x}+g+v_{\mathrm{V}} \frac{\partial^{2} u_{\mathrm{V}}}{\partial y^{2}}=-\frac{\rho_{\infty}}{\rho_{V}} g+g+v_{\mathrm{V}} \frac{\partial^{2} u_{\mathrm{V}}}{\partial y^{2}}
$$

Energy equation:

$$
u_{\mathrm{V}} \frac{\partial T_{\mathrm{V}}}{\partial x}+v_{V} \frac{\partial T_{\mathrm{V}}}{\partial y}=\alpha_{V}\left(\frac{\partial^{2} T_{\mathrm{V}}}{\partial x^{2}}+\frac{\partial^{2} T_{\mathrm{V}}}{\partial y^{2}}\right)
$$

Mass transport equation:

$$
u_{\mathrm{V}} \frac{\partial W_{\mathrm{eV}}}{\partial x}+v_{\mathrm{V}} \frac{\partial W_{\mathrm{eV}}}{\partial y}=D\left(\frac{\partial^{2} W_{\mathrm{eV}}}{\partial x^{2}}+\frac{\partial^{2} W_{\mathrm{eV}}}{\partial y^{2}}\right)
$$

where $D$ is the binary diffusion coefficient, $\mathrm{m}^{2} \cdot \mathrm{s}^{-1} ; \rho_{\infty}$ is the density of the main vapor, $\mathrm{kg} \cdot \mathrm{m}^{-3} ; u_{\mathrm{V}}$ is the vapor velocity along the $x$-direction, $\mathrm{m} \cdot \mathrm{s}^{-1} ; v_{\mathrm{V}}$ is the vapor velocity along the $y$-direction, $\mathrm{m} \cdot \mathrm{s}^{-1} ; W_{\mathrm{eV}}$ is the ethanol vapor concentration in the vapor diffusion layer, $\%$; $\rho_{\mathrm{V}}$ is the density of the vapor in the vapor diffusion layer, $\mathrm{kg} \cdot \mathrm{m}^{-3} ; \alpha_{\mathrm{V}}$ is the vapor thermal diffusivity in the vapor diffusion layer, $\mathrm{m}^{2} \cdot \mathrm{s}^{-1}$; $v_{\mathrm{V}}$ is the vapor kinematic viscosity in the vapor diffusion layer, $\mathrm{m}^{2} \cdot \mathrm{s}^{-1} ; T_{\mathrm{V}}$ is the vapor temperature in the vapor diffusion layer, $\mathrm{K} ; P$ is the vapor pressure in the vapor diffusion layer, $\mathrm{Pa}$; and $U_{\infty}$ is the velocity of the main vapor, $\mathrm{m} \cdot \mathrm{s}^{-1}$.

Solving the above equations directly is difficult. Therefore, a similarity transformation method is employed to simplify these equations. A new variable $\eta$ is introduced as follows:

$$
\eta=y\left(\frac{U_{\infty}}{v_{\mathrm{V}} x}\right)^{1 / 4}
$$

$\Psi$ is defined as the stream function, so

$$
u_{\mathrm{V}}=\partial \psi / \partial y, v_{\mathrm{V}}=-\partial \psi / \partial x
$$


(1) Several functions are also introduced based on $\eta$ :

$$
\begin{gathered}
F(\eta)=\frac{\psi}{\left(v_{\mathrm{V}} U_{\infty} x\right)^{1 / 2}} \\
\Theta(\eta)=\frac{T_{\infty}-T}{T_{\infty}-T_{\mathrm{i}}} \\
\Phi(\eta)=\frac{W_{\mathrm{eV}}-W_{\mathrm{e} \infty}}{W_{\mathrm{eiV}}-W_{\mathrm{e} \infty}}
\end{gathered}
$$

where $W_{\mathrm{e} \infty}$ is the ethanol vapor concentration of the main vapors, $\%$.

(2) Equation (18) is substituted into Equation (17). Then,

$$
\begin{gathered}
u_{\mathrm{V}}=U_{\infty} F^{\prime} \\
v_{\mathrm{V}}=0.5\left(v_{\mathrm{V}} U_{\infty}\right)^{0.5}\left[y x^{-1}\left(\frac{U_{\infty}}{v_{\mathrm{V}}}\right)^{0.5} F^{\prime}-x^{-0.5} F\right]
\end{gathered}
$$

(3) Then the governing equations can be simplified as follows:

$$
\begin{gathered}
F^{\prime \prime \prime}+0.5 F F^{\prime \prime}=0 \\
\Theta^{\prime \prime}+0.5 \operatorname{Pr} \Theta^{\prime}=0 \\
\Phi^{\prime \prime}+0.5 S c F \Phi^{\prime}=0 \\
\operatorname{Pr}=\frac{{ }^{\mathrm{p}} \mu}{\lambda} \\
S c=\frac{\mu}{\rho D}
\end{gathered}
$$

where $c_{\mathrm{p}}$ is the specific heat at constant pressure, $\mathrm{J} \cdot \mathrm{kg}^{-1} \cdot \mathrm{K}^{-1}$; and $\mu$ is the dynamic viscosity, Pa.s.

Since the conduction heat transfer is much smaller than the condensation heat transfer in the vapor diffusion layer, the energy Equation (24) can be neglected.

\subsubsection{Boundary Conditions}

The boundary conditions of the aforementioned governing equations are included in two parts: the vapor-liquid interface and the main vapors.

(1) At $y=0$ (vapor-liquid interface)

$$
\begin{gathered}
W_{\mathrm{eV}}=W_{\mathrm{eiV}} \\
u_{\mathrm{V}}=0
\end{gathered}
$$

where $W_{\mathrm{eiV}}$ is the ethanol vapor concentration at the vapor-liquid interface, $\%$.

By similarity transformation, Equations (28)-(29) can be written

$$
\begin{aligned}
& \Phi(0)=1 \\
& F^{\prime}(0)=0
\end{aligned}
$$

The mass flux through the vapor-liquid interface includes the one by diffusion and the one by convection. For ethanol, the mass flux by convection is $-\rho_{\mathrm{eV}} v_{\mathrm{V}}$, and the mass flux by diffusion 
is $\rho_{\mathrm{V}} D \frac{d W_{\mathrm{eV}}}{d y}$, so the total mass flux is $m_{\mathrm{e}}=-\rho_{\mathrm{eV}} v_{\mathrm{V}}+\rho_{\mathrm{V}} D \frac{d W_{\mathrm{eV}}}{d y}$. For water, the total mass flux is $m_{\mathrm{w}}=-\rho_{\mathrm{wV}} v_{\mathrm{V}}+\rho_{\mathrm{V}} D \frac{d W_{\mathrm{wV}}}{d y}$. Then the total mass flux through the vapor-liquid interface is as follows:

$$
\begin{gathered}
m=m_{\mathrm{w}}+m_{\mathrm{e}}=-\rho_{\mathrm{wV}} v_{\mathrm{V}}+\rho_{\mathrm{V}} D \frac{d W_{\mathrm{wV}}}{d y}-\rho_{\mathrm{eV}} v_{\mathrm{V}}+\rho_{\mathrm{V}} D \frac{d W_{\mathrm{eV}}}{d y} \\
=-\left(\rho_{\mathrm{wV}}+\rho_{\mathrm{eV}}\right) v_{\mathrm{V}}+\rho_{\mathrm{V}} D \frac{d\left(1-W_{\mathrm{eV}}\right)}{d y}+\rho_{\mathrm{V}} D \frac{d W_{\mathrm{eV}}}{d y}=-\rho_{\mathrm{V}} v_{\mathrm{V}}
\end{gathered}
$$

According to the mass balance during the condensation process, the total mass flux of the condensate is as follows:

$$
m=\frac{q}{h_{\mathrm{fg}}}
$$

Then

$$
v_{\mathrm{V}}=-\frac{q}{\rho_{\mathrm{V}} h_{f g}}
$$

Along with the vapor-liquid interface, the mean value for the unit length is as follows:

$$
v_{V}(0)=-0.5\left(v_{V} U_{\infty}\right)^{0.5} F(0) \frac{1}{1} \int_{0}^{1} x^{-0.5} d x=-\left(v_{V} U_{\infty}\right)^{0.5} F(0)
$$

Therefore,

$$
F(0)=\frac{v_{V}(0)}{-\left(v_{V} U_{\infty}\right)^{0.5}}
$$

(2) At $y=\infty$ (the main vapors)

$$
\begin{gathered}
W_{\mathrm{eV}}=W_{\mathrm{e} \infty} \\
u_{\mathrm{V}}=U_{\infty}
\end{gathered}
$$

The boundary equations can be simplified as follows:

$$
\begin{aligned}
& \Phi(\infty)=0 \\
& F^{\prime}(\infty)=1
\end{aligned}
$$

(3) The component mass balance at the vapor-liquid interface

All the components in the condensate layer are through the vapor-liquid interface. Thus, the ratio of concentration is equal to the ratio of component mass flux at the vapor-liquid interface.

$$
\frac{W_{\mathrm{eiL}}}{W_{\mathrm{wiL}}}=\frac{m_{\mathrm{e}}}{m_{\mathrm{w}}}
$$

where $W_{\text {eiL }}$ is the ethanol liquid concentration at the vapor-liquid interface, determined from the vapor-liquid phase equilibrium diagrams, $\% ; W_{\text {wiL }}$ is the water liquid concentration at the vapor-liquid interface, $W_{\mathrm{wiL}}=1-W_{\mathrm{eiL}}, \% ; m_{\mathrm{e}}$ is the mass flux of the ethanol through the vapor-liquid interface, $\mathrm{kg} \cdot \mathrm{s}^{-1} ; m_{\mathrm{w}}$ is the mass flux of the water through the vapor-liquid interface, $\mathrm{kg} \cdot \mathrm{s}^{-1}$; and $m$ is the total mass flux through the vapor-liquid interface, $\mathrm{kg} \cdot \mathrm{s}^{-1}$.

\subsection{The Solution Procedure of the Model}

Figure 2 shows the calculation process of the proposed model. First, a vapor-liquid interface temperature $T_{\mathrm{i}}$ is assumed, and the mean heat flux of the condensate layer is calculated. Then, the boundary conditions at the vapor-liquid interface can be derived, as well as that for the upper boundary of the vapor diffusion layer. On this basis, Equations (23) and (25) can be solved. With the results integrated into the component conservation conditions at the interface, the ethanol liquid concentration can be obtained. A new interface temperature $T_{\mathrm{i} 2}$ is determined by the ethanol-water 
phase equilibrium diagram. If the difference between $T_{\mathrm{i}}$ and $T_{\mathrm{i} 2}$ is less than the set value, then the assumed value of $T_{\mathrm{i}}$ can be considered as the actual vapor-liquid interface temperature. Otherwise, the value of $T_{\mathrm{i}}$ should be reset and recalculated until the difference is less than the set value.

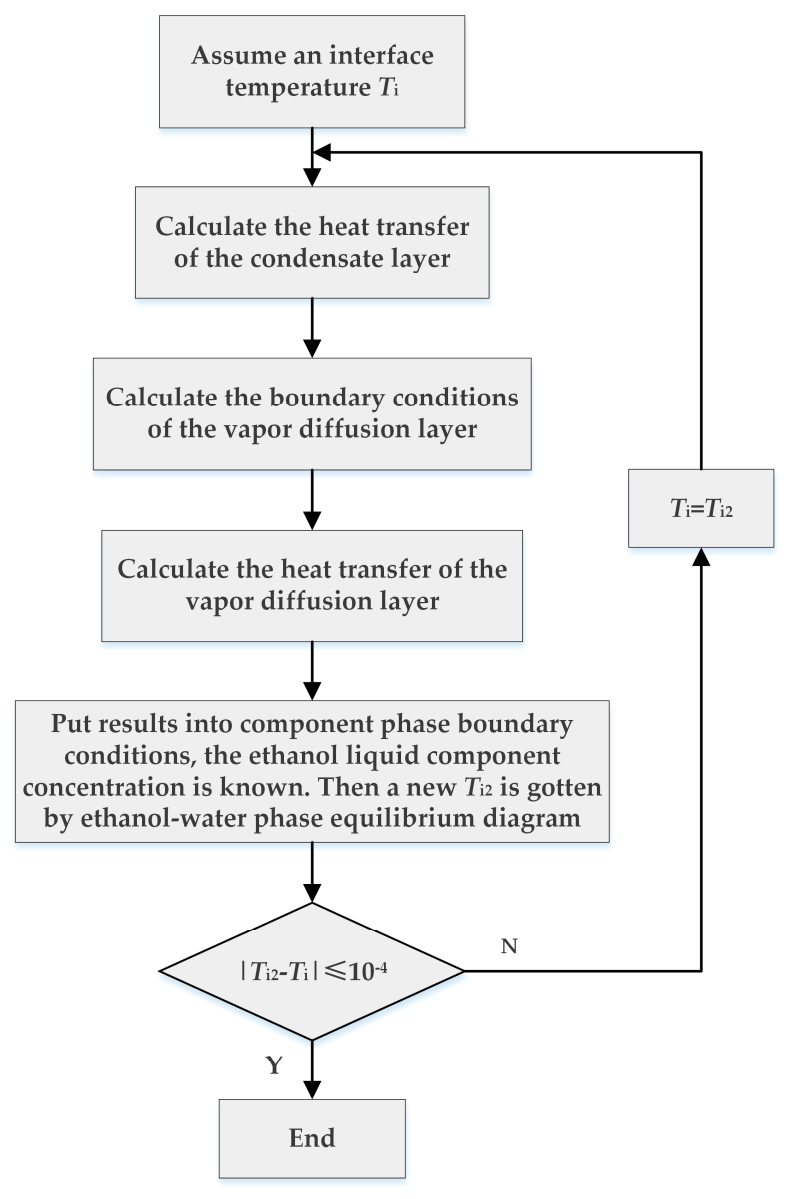

Figure 2. Calculation process of the proposed model.

The qualitative temperature and concentration of the condensate layer can be determined by Ref. [30]:

$$
\begin{gathered}
T_{\mathrm{L}}^{*}=T_{\mathrm{w}}+(1 / 3)\left(T_{\mathrm{i}}-T_{\mathrm{w}}\right) \\
W_{\mathrm{eL}}^{*}=W_{\mathrm{eiL}}
\end{gathered}
$$

The qualitative temperature and concentration of the vapor diffusion layer are as follows:

$$
\begin{gathered}
T_{\mathrm{V}}^{*}=\frac{1}{2}\left(T_{\infty}+T_{\mathrm{i}}\right) \\
W_{\mathrm{eV}}^{*}=\frac{1}{2}\left(W_{\mathrm{e} \infty}+W_{\mathrm{eiV}}\right)
\end{gathered}
$$

\section{Results and Discussion}

The heat transfer model presented in this paper is for the Marangoni condensation of the water-ethanol mixture vapors. In this model, the specific physical properties and the parameters that affect the condensation modes are considered. The vapor-liquid interface temperature is also an important intermediate parameter. Therefore, investigating the vapor-liquid interface temperature and the condensation heat transfer coefficient is important. 


\subsection{Vapor-Liquid Interface Temperature}

Figure 3 shows the calculated results of the vapor-liquid interface temperature under different conditions. The vapor-liquid interface temperature declines rapidly up to a certain value, and then remains almost constant, with the increase in the vapor-to-surface temperature difference. In the decline region, the vapor-liquid interface temperature nearly drops linearly. The vapor-liquid interface temperature decreases from the dew-point temperature to the bubble-point temperature with the increase in the vapor-to-surface temperature difference. The corresponding vapor-to-surface temperature difference that is represented by the intersection point of two straight lines in Figure 3, where the vapor-liquid interface temperature just approaches the bubble-point temperature, is related to the temperature difference between the dew-point and the bubble-point. Figure 4 shows the comparisons of the vapor-to-surface temperature difference and the temperature difference between the dew-point and the bubble-point under different conditions. As shown in Figure 4, with the increase in the ethanol vapor concentration, the corresponding vapor-to-surface temperature difference increases first and then decreases. The maximum value is observed at the ethanol vapor concentration of $20 \%$. The vapor-to-surface temperature difference is slightly larger than the temperature difference between the dew-point and the bubble-point, and the deviation is about $0.5-1.5 \mathrm{~K}$.

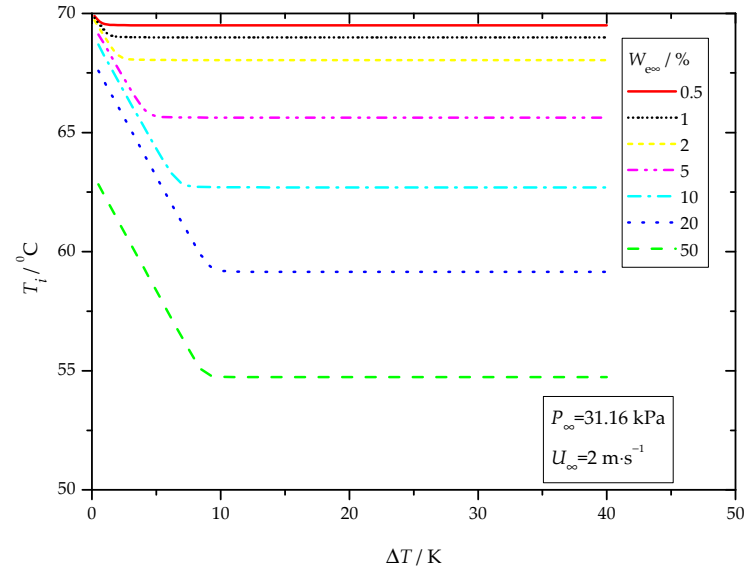

(a)

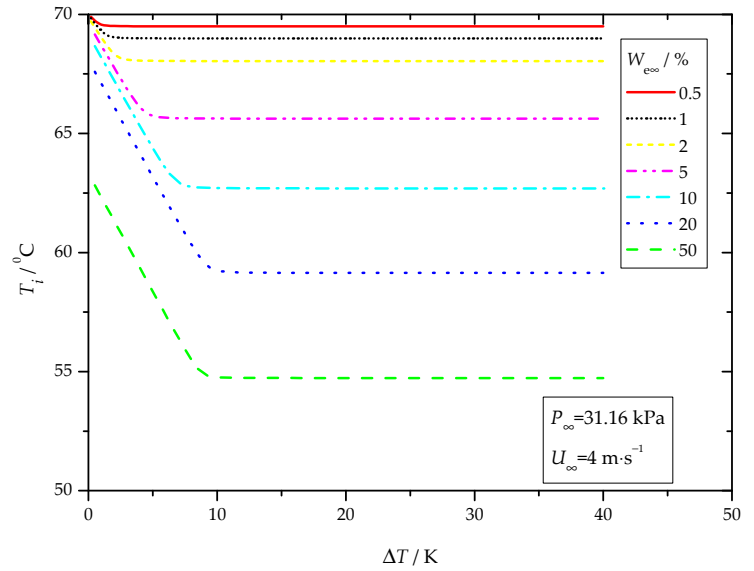

(b)

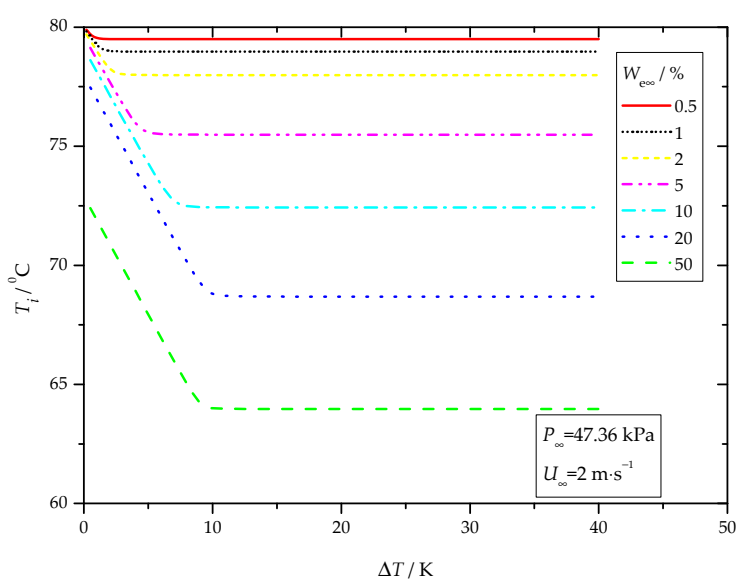

(c)

Figure 3. Calculation results of vapor-liquid interface temperatures at (a) $P_{\infty}=31.16 \mathrm{kPa}, U_{\infty}=2 \mathrm{~m} \cdot \mathrm{s}^{-1}$; (b) $P_{\infty}=31.16 \mathrm{kPa}, U_{\infty}=4 \mathrm{~m} \cdot \mathrm{s}^{-1}$; (c) $P_{\infty}=47.36 \mathrm{kPa}, U_{\infty}=2 \mathrm{~m} \cdot \mathrm{s}^{-1}$. 


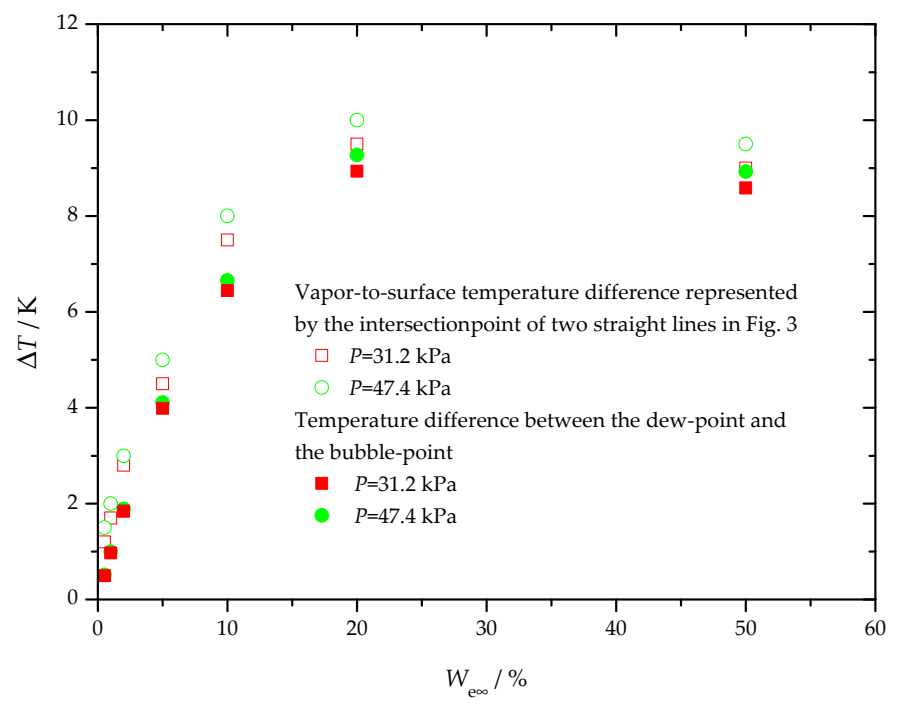

Figure 4. Comparison of vapor-to-surface temperature difference represented by the intersection point of two straight lines in Figure 3 and the temperature difference between the dew-point and the bubble-point.

\subsection{Condensation Heat Transfer Coefficient}

Figure 5 shows the condensation heat transfer coefficients of water-ethanol vapor mixtures calculated by the present model under different conditions. As shown in Figure 5, the heat transfer coefficients first remain almost constant, decrease slightly, increase rapidly and reach the maximum values, and finally decrease gently, with the increase in the vapor-to-surface temperature difference. In the condensation heat transfer characteristic curve, two characteristic points are found, namely, the start point of the rapid increase region of heat transfer and the maximum point of the heat transfer coefficient. As the ethanol vapor concentration increases, the vapor-to-surface temperature differences that correspond to the two characteristic points also increase first and then decrease, and they reach peak values when the ethanol vapor concentration is $20 \%$. The variation trend of the heat transfer coefficient with vapor-to-surface temperature difference is the same as that of the experimental results. Figure 5 also presents the effect of ethanol vapor concentrations on condensation heat transfer coefficients. For the typical ethanol vapor concentrations presented in Figure 5, the calculated condensation heat transfer coefficients decrease with the increase in the ethanol vapor concentration, and the largest one appears at the concentration of $0.5 \%$. This finding is different from the experimental results, where the largest heat transfer coefficient appears at the concentration of $1 \%$, and the second largest one appears at the concentration of $2 \%$. This condition is mainly due to the deviation of the condensation mode parameters adopted in the model, especially for the low ethanol vapor concentration range. 


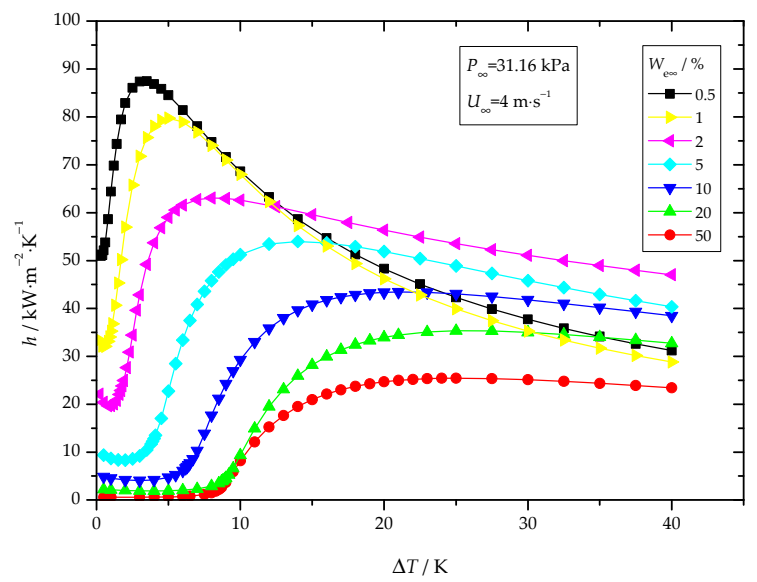

(a)

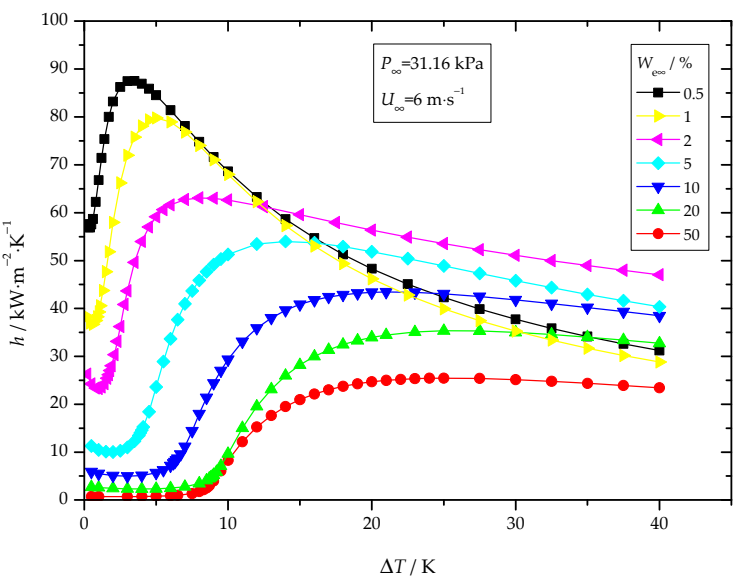

(b)

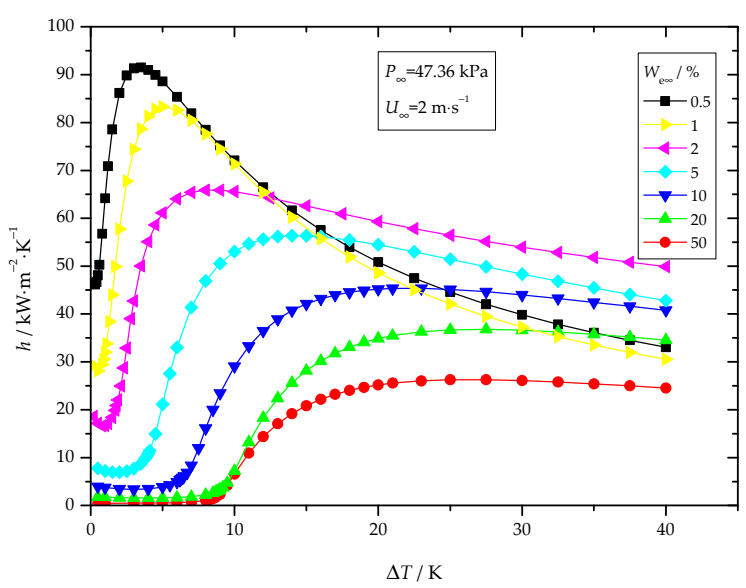

(c)

Figure 5. Calculation results of condensation heat transfer coefficients at (a) $P_{\infty}=31.16 \mathrm{kPa}$, $U_{\infty}=4 \mathrm{~m} \cdot \mathrm{s}^{-1}$; (b) $P_{\infty}=31.16 \mathrm{kPa}, U_{\infty}=6 \mathrm{~m} \cdot \mathrm{s}^{-1}$; (c) $P_{\infty}=47.36 \mathrm{kPa}, U_{\infty}=2 \mathrm{~m} \cdot \mathrm{s}^{-1}$.

Figure 6 shows the comparison of the calculated results of the condensation heat transfer coefficients with the experimental data of Ref. [11]. As shown in Figure 6, the variation trend of the calculated condensation heat transfer coefficients with vapor-to-surface temperature difference is basically consistent with the experimental results. However, the specific values of these results have some differences. The calculated heat transfer coefficients are smaller than those from experiments under the condition of large ethanol vapor concentration and small vapor-to-surface temperature difference. However, near the region that corresponds to the maximum heat transfer coefficient, the two values are close to each other. Figure 7 shows the relative tolerance between the calculated results of the maximum heat transfer coefficient and the experimental results. As shown in Figure 7, the deviation is within $\pm 25 \%$, except for a few ethanol vapor concentrations. Marangoni condensation is not an entirely dropwise condensation process, which is why the condensation modes vary when the vapor-to-surface temperature difference changes. As shown in Refs. [7,29], when the vapor-to-surface temperature difference is in the small or large range, the condensation modes are usually close to filmwise, such as streak, wavy film, etc. Large differences occur as the calculation model is based on dropwise condensation mode in these ranges. When the vapor-to-surface temperature difference is in the range where the condensation heat transfer coefficients reach peak values, typical and complete dropwise condensation modes will occur. This could be the reason for the differences between 
the calculation results and experimental results are small in the middle range of vapor-to-surface temperature difference but larger in the other range. Thus, this model could be used to predict the heat transfer characteristic of Marangoni dropwise condensation even though the calculation results of the proposed model deviated from the experimental results in some cases, while in some subcooling region where have the maximum condensation heat transfer coefficient.

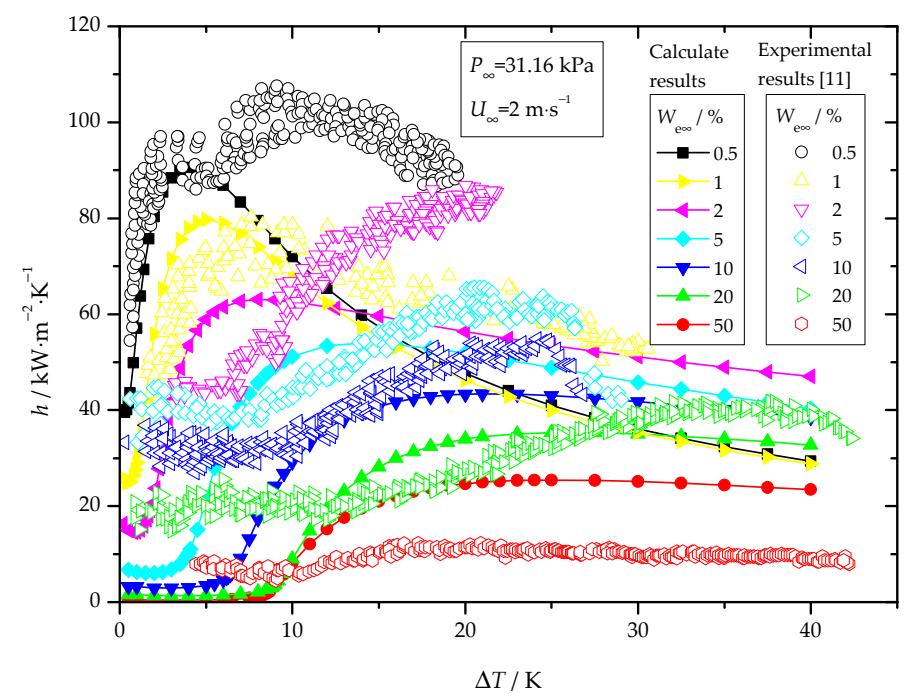

Figure 6. Comparison of condensation heat transfer coefficients between the calculation results and the existing experimental results.

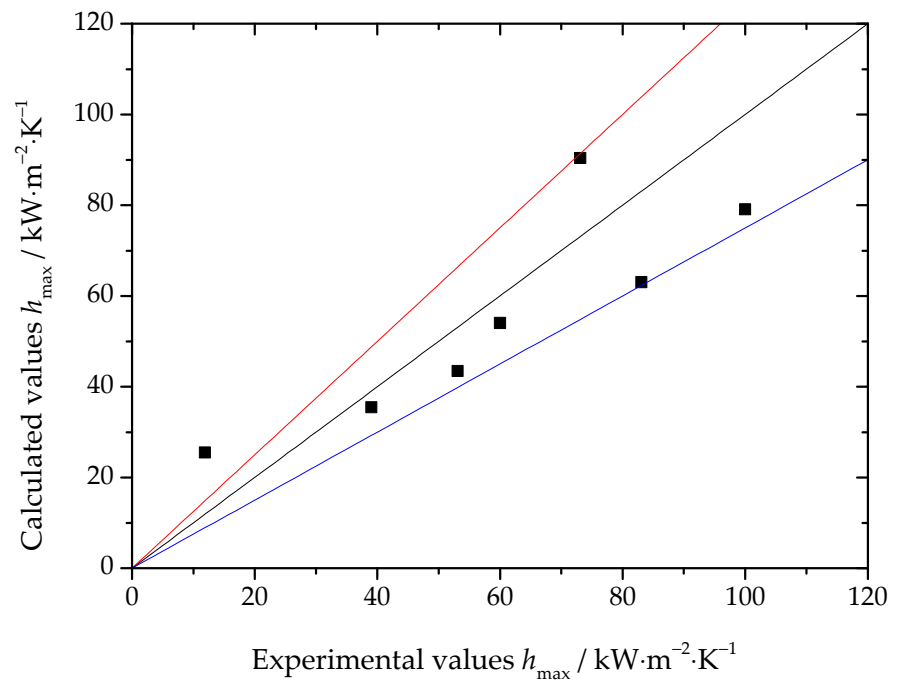

Figure 7. Deviation of the maximum condensation heat transfer coefficients between the calculation results and experiment results.

Figure 8 shows the effect of vapor velocities on the condensation heat transfer coefficients. The heat transfer coefficients increase with the increase in the vapor velocity but the growth range is not obvious. Probably because of the lack of the detailed effect rule of the vapor velocity on the condensation modes, and the difference of condensation modes at different vapor velocities is neglected in the present model. Figure 9 compares the calculation values of condensation heat transfer coefficients under different vapor pressures. As shown in Figure 9, the heat transfer coefficients increase with the increase in the vapor pressure. The effect of the vapor pressure is obvious in the middle region of the vapor-to-surface temperature difference where the heat transfer coefficients reach peak values. 


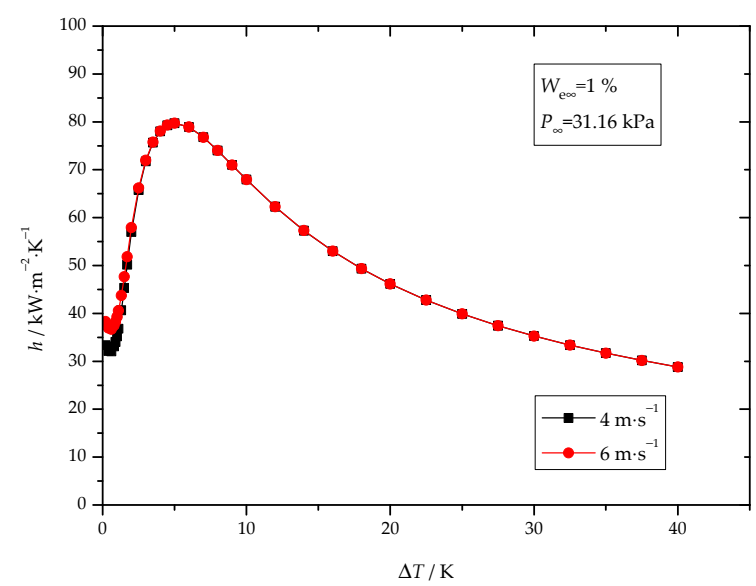

(a)

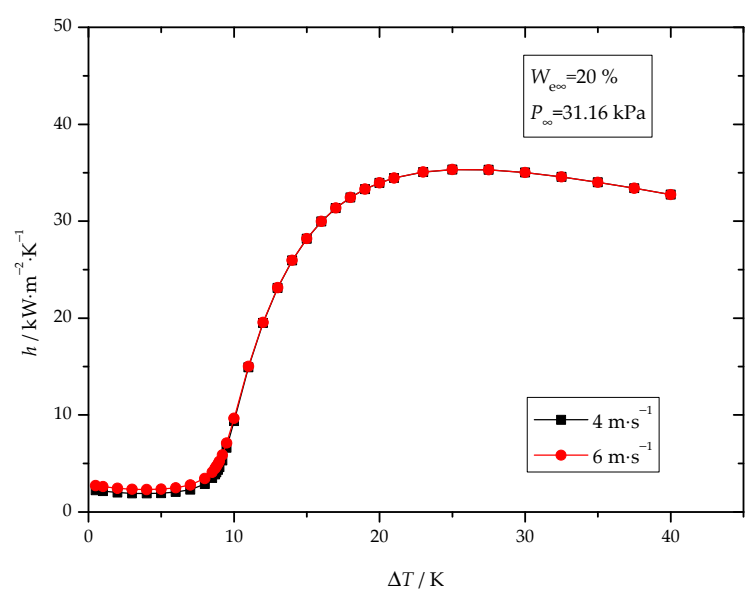

(b)

Figure 8. Calculated condensation heat transfer coefficients on different velocities at (a) $W_{\mathrm{e} \infty}=1 \%$ $P_{\infty}=31.16 \mathrm{kPa} ;(\mathbf{b}) W_{\mathrm{e} \infty}=20 \% P_{\infty}=31.16 \mathrm{kPa}$.

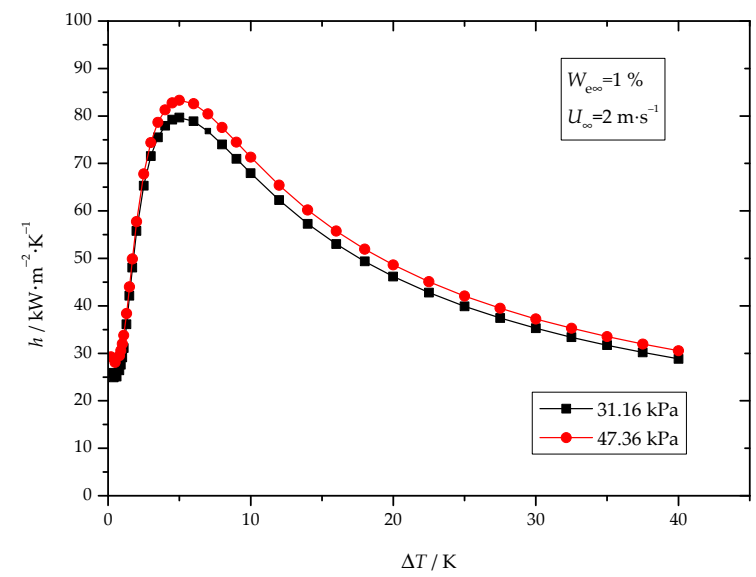

(a)

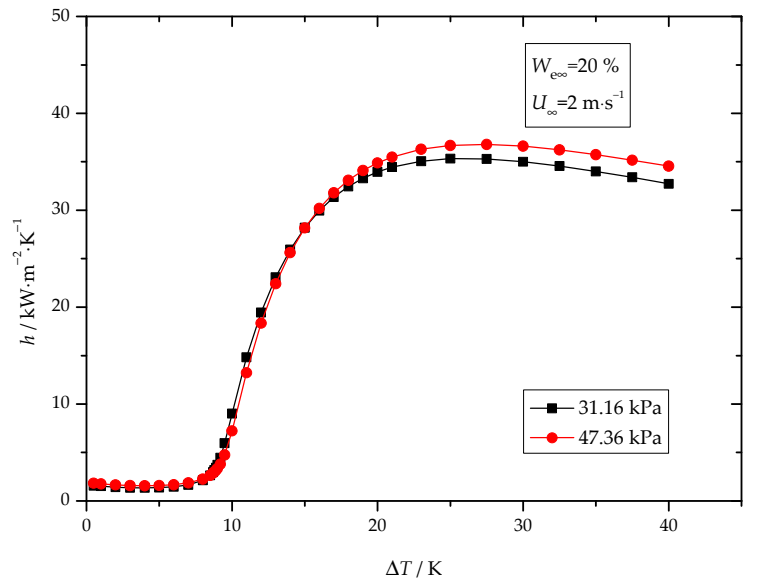

(b)

Figure 9. Calculated condensation heat transfer coefficients on different pressures at (a) $W_{\mathrm{e} \infty}=1 \%$ $U_{\infty}=2 \mathrm{~m} \cdot \mathrm{s}^{-1} ;(\mathbf{b}) W_{\mathrm{e} \infty}=20 \% U_{\infty}=2 \mathrm{~m} \cdot \mathrm{s}^{-1}$.

Several reasons are responsible for the deviation between the calculation results of the present model and the experimental results. First, insufficient data that can precisely describe the condensation modes are available on the quantitative studies about Marangoni condensation modes. It can be found that the adjustable parameters of condensation modes mainly include the minimum drop radius, the maximum drop radius, and the drop size distribution function. The drop size distribution function proposed by Le Ferve and Rose [34] has been widely accepted by many researchers, but it is based on the dropwise condensation of pure vapor. The experimental results of drop size presented by different researchers are not unified, and the actual shapes of the maximum drop radius are not standard spherical caps. Furthermore, due to the limitation of measurement techniques, no direct measurement results of the minimum drop radius are available. Moreover, the detailed effect rule of the influencing factors on condensation modes, including vapor velocity, and vapor pressure, is neglected due to a lack of quantitative studies. The shapes of the drops in Marangoni dropwise condensation are not strictly hemispherical, thereby also affecting the thermal resistance of the condensate. Second, the condensate layer of Marangoni condensation is treated as dropwise condensation. But in the traditional calculation model of dropwise condensation, only the heat transferred through the drops is counted. The significant difference between Marangoni condensation and traditional dropwise 
condensation could be that a thin condensate film is present at the bottom of the condensate layer in Marangoni condensation, But in the present model, the influence of this thin film is neglected. Third, the influences of the Marangoni effect and the movement of the drops on the vapor diffusion layer are not considered in this model.

The theoretical model developed in this paper can basically reflect the influences of vapor-to-surface temperature difference, vapor concentration, vapor pressure, and vapor velocity on the heat transfer characteristics of Marangoni dropwise condensation. Although some differences exist between the calculation results and experimental results, the prediction deviation of the model is acceptable in the range of vapor-to-surface temperature difference that researchers usually focus on, where the condensation heat transfer coefficients reach peak values.

\section{Conclusions}

With the complexity of Marangoni condensation, there are no systematic theories or models to accurately predict the heat transfer characteristic. In this paper, an attempt was made to develop the Marangoni dropwise condensation heat transfer model for water-ethanol mixture vapors. In this model, Marangoni condensation was considered as dropwise condensation of mixture vapors, and the entire condensation heat transfer area was divided into two parts, which including the condensate layer and the vapor diffusion layer.

The calculation results showed that this model can reflect the influences of vapor-to-surface temperature difference, vapor concentration, vapor pressure, and vapor velocity on the heat transfer characteristics of Marangoni dropwise condensation. Quantitative studies about Marangoni condensation modes are lacking, which is why the specific values of the condensation heat transfer coefficients calculated by the present model have some differences with those of the experimental results, but the prediction deviation was acceptable in the range of vapor-to-surface temperature difference where have the maximum heat transfer coefficients which most researchers focus on. The deviation of maximum heat transfer coefficients between the prediction results and the experimental results is within $\pm 25 \%$, except for a few ethanol vapor concentrations.

Further study is planned to obtain more quantitative results about the minimum drop radius and the maximum drop radius by using microcosmic methods, which can help establish the quantitative and qualitative relationships between the Marangoni condensation modes and the heat transfer characteristics. Moreover, several important factors, such as the thin condensate film under the drops, the effect of movement drop on the vapor diffusion layer, and the intensification of mass transfer through the vapor-liquid interface caused by the Marangoni effect, should be considered more carefully. The model presented in this study could help to obtain a more fundamental description of the mechanism in Marangoni dropwise condensation and to control the heat transfer characteristics by active regulation.

Author Contributions: Conceptualization, J.W. and G.L.; methodology, Z.M. and Y.L.; software, W.L.; validation, W.L.; investigation, Z.M. and Y.L.; resources, G.L.; writing—original draft preparation, Z.M.; writing-review and editing, J.W.; supervision, J.W.; project administration, G.L.; funding acquisition, J.W. and G.L. All authors have read and agreed to the published version of the manuscript.

Funding: This research was funded by the China Postdoctoral Science Foundation (Grant Number 2020M673412), the National Natural Science Foundation of China (grant number 51876171) and the Natural Science Basic Research Project in Shaanxi Province, China (grant number 2018JM5157).

Acknowledgments: The authors are very grateful to Y. Utaka at Tianjin University for his guidance in this research field.

Conflicts of Interest: The authors declare no conflict of interest. 


\section{Nomenclature}

\begin{tabular}{|c|c|}
\hline$D$ & the diffusion coefficient $\left(\mathrm{m}^{2} \cdot \mathrm{s}^{-1}\right)$ \\
\hline F & function \\
\hline$g$ & gravitational acceleration $\left(\mathrm{m} \cdot \mathrm{s}^{-2}\right)$ \\
\hline$h$ & heat transfer coefficient $\left(\mathrm{kW} \cdot \mathrm{m}^{-2} \cdot \mathrm{K}^{-1}\right)$ \\
\hline$h_{\mathrm{fg}}$ & heat latent $\left(\mathrm{J} \cdot \mathrm{kg}^{-1}\right)$ \\
\hline$m$ & $\operatorname{mass}$ flux $\left(\mathrm{kg} \cdot \mathrm{s}^{-1}\right)$ \\
\hline$T$ & temperature $(\mathrm{K})$ \\
\hline$P$ & vapor pressure in vapor diffusion layer $(\mathrm{Pa})$ \\
\hline $\operatorname{Pr}$ & Prandtl number \\
\hline$q$ & heat transfer rate $(\mathrm{W})$ \\
\hline$r$ & radius of the drop $(\mathrm{m})$ \\
\hline Sc & Schmidt number \\
\hline$U$ & velocity of the main vapor $\left(\mathrm{m} \cdot \mathrm{s}^{-1}\right)$ \\
\hline$u$ & velocity along the $x$-direction $\left(\mathrm{m} \cdot \mathrm{s}^{-1}\right)$ \\
\hline$v$ & velocity along the $y$-direction $\left(\mathrm{m} \cdot \mathrm{s}^{-1}\right)$ \\
\hline$W$ & concentration $(\%)$ \\
\hline \multicolumn{2}{|c|}{ Greek Symbols } \\
\hline$\alpha$ & vapor thermal diffusivity $\left(\mathrm{m}^{2} \cdot \mathrm{s}^{-1}\right)$ \\
\hline$\gamma$ & $\begin{array}{l}\text { the fraction of surface area covered by drops with } \\
\text { radius larger than } r(\%)\end{array}$ \\
\hline$\Delta T$ & temperature difference $(\mathrm{K})$ \\
\hline$\eta$ & new variable \\
\hline$\Theta$ & function \\
\hline$\lambda$ & thermal conductivity $\left(\mathrm{W} \cdot \mathrm{m}^{-1} \cdot \mathrm{K}^{-1}\right)$ \\
\hline$\mu$ & the dynamic viscosity $(\mathrm{Pa} \cdot \mathrm{s})$ \\
\hline$v$ & vapor kinematic viscosity $\left(\mathrm{m}^{2} \cdot \mathrm{s}^{-1}\right)$ \\
\hline$\rho$ & density $\left(\mathrm{kg} \cdot \mathrm{m}^{-3}\right)$ \\
\hline$\sigma$ & surface tension $\left(\mathrm{N} \cdot \mathrm{m}^{-1}\right)$ \\
\hline$\Phi$ & function \\
\hline$\Psi$ & stream function \\
\hline \multicolumn{2}{|c|}{ Subscripts } \\
\hline $\mathrm{b}$ & through the drop \\
\hline c & vapor-liquid interfacial curvature \\
\hline cs & condensing surface \\
\hline $\mathrm{d}$ & vapor-liquid interfacial resistance \\
\hline e & ethanol \\
\hline $\mathrm{eV}$ & ethanol vapor \\
\hline eL & ethanol liquid \\
\hline eiL & ethanol liquid at the interface \\
\hline eiV & ethanol vapor at the interface \\
\hline $\mathrm{i}$ & vapor-liquid interface \\
\hline $\mathrm{L}$ & liquid \\
\hline $\max$ & maximum \\
\hline $\min$ & minimum \\
\hline V & vapor \\
\hline $\mathrm{w}$ & water \\
\hline $\mathrm{wV}$ & water vapor \\
\hline$w L$ & water liquid \\
\hline$\infty$ & main vapor \\
\hline
\end{tabular}




\section{References}

1. Wang, J.S.; Ma, Z.Q.; Li, G.; Sundén, B.; Yan, J.J. Improved modeling of heat transfer in dropwise condensation. Int. J. Heat Mass Transf. 2020, 155, 119719. [CrossRef]

2. Ahlers, M.; Buck-Emden, A.; Bart, H.J. Is dropwise condensation feasible? A review on surface modifications for continuous dropwise condensation and a profitability analysis. J. Adv. Res. 2019, 16,1-13. [CrossRef] [PubMed]

3. Mirkovich, V.V.; Missen, R.W. Non-filmwise condensation of binary vapors of miscible liquids. Can. J. Chem. Eng. 1961, 39, 86-87. [CrossRef]

4. Utaka, Y.; Terachi, N. Measurement of condensation characteristic curves for binary mixture of steam and ethanol vapor. Heat Transf. Jpn. Res. 1995, 24, 57-67.

5. Kim, K.J.; Lefsaker, A.M.; Razani, A.; Stone, A. The effective use of heat transfer additives for steam condensation. Appl. Therm. Eng. 2001, 21, 1863-1874. [CrossRef]

6. Philpott, C.; Deans, J. The enhancement of steam condensation heat transfer in a horizontal shell and tube condenser by addition of ammonia. Int. J. Heat Mass Transf. 2004, 47, 3683-3693. [CrossRef]

7. Utaka, Y.; Wang, S.X. Characteristic curves and the promotion effect of ethanol addition on steam condensation heat transfer. Int. J. Heat Mass Transf. 2004, 47, 4507-4516. [CrossRef]

8. Vemuri, S.; Kim, K.J.; Kang, Y.T. A study on effective use of heat transfer additives in the process of steam condensation. Int. J. Refrig. 2006, 29, 724-734. [CrossRef]

9. Murase, T.; Wang, H.S.; Rose, J.W. Marangoni condensation of steam-ethanol mixtures on a horizontal tube. Int. J. Heat Mass Transf. 2007, 50, 3774-3779. [CrossRef]

10. Hu, S.H.; Yan, J.J.; Wang, J.S.; Li, Y.; Liu, J.P. Effect of temperature gradient on Marangoni condensation heat transfer for ethanol-water mixtures. Int. J. Multiph. Flow. 2007, 33, 935-947. [CrossRef]

11. Yang, Y.S.; Yan, J.J.; Wu, X.Z.; Hu, S.H. Effects of vapor pressure on Marangoni condensation of steam-ethanol mixtures. J. Thermophys. Heat Transf. 2008, 22, 247-253. [CrossRef]

12. Wang, J.S.; Yan, J.J.; Li, Y.; Hu, S.H. Experimental investigation of Marangoni condensation of ethanol-water mixture vapors on vertical tube. Heat Mass Transf. 2009, 45, 1533-1541. [CrossRef]

13. Wang, J.S.; Yan, J.J.; Hu, S.H.; Liu, J.P. Marangoni condensation heat transfer of water-ethanol mixtures on a vertical surface with temperature gradients. Int. J. Heat Mass Transf. 2009, 52, 2324-2334. [CrossRef]

14. Utaka, Y.; Wang, S.X. Effect of ethanol mass fraction on condensation heat transfer characteristics for water-ethanol binary vapor mixture. Trans. JSRAE 2011, 18, 127-134.

15. Ma, X.H.; Lan, Z.; Xu, W.; Wang, M.Z.; Wang, S.F. Effect of surface free energy difference on steam-ethanol mixture condensation heat transfer. Int. J. Heat Mass Transf. 2012, 55, 531-537. [CrossRef]

16. Deans, J.; Martin, P.J.; Norris, S. The condensation of steam containing low concentrations of trimethylamine. Int. J. Heat Mass Transf. 2013, 61, 381-388. [CrossRef]

17. Ali, H.; Wang, H.S.; Briggs, A.; Rose, J.W. Effects of vapor velocity and pressure on Marangoni condensation of steam-ethanol mixtures on a horizontal tube. J. Heat Transf. 2013, 135. [CrossRef]

18. Chen, X.P.; Wang, J.S.; Qin, J.C.; Chong, D.T.; Huang, R.H.; Yan, J.J. Experimental study on condensation heat transfer of ethanol-water vapor mixtures on vertical micro-tubes. Int. J. Thermophys. 2015, 36, 1598-1617. [CrossRef]

19. Hu, S.H.; Ma, X.R.; Zhou, W.Q. Condensation heat transfer of ethanol-water vapor in a plate heat exchanger. Appl. Therm. Eng. 2017, 113, 1047-1055. [CrossRef]

20. Ali, H.; Kamran, M.S.; Ali, H.M.; Imran, S. Condensation heat transfer enhancement using steam-ethanol mixtures on horizontal finned tube. Int. J. Therm. Sci. 2019, 140, 87-95. [CrossRef]

21. Sarafraz, M.M.; Peyghambarzadeh, S.M. Experimental study on subcooled flow boiling heat transfer to water-diethylene glycol mixtures as a coolant inside a vertical annulus. Exp. Therm. Fluid Sci. 2013, 50, 154-162. [CrossRef]

22. Yang, B.; Sarafraz, M.M.; Arjomandi, M. Marangoni effect on the thermal performance of glycerol/water mixture in microchannel. Appl. Therm. Eng. 2019, 161, 114142. [CrossRef]

23. Sarafraz, M.M.; Arjomandi, M. Contact angle and heat transfer characteristics of a gravity-driven film flow of a particulate liquid metal on smooth and rough surfaces. Appl. Therm. Eng. 2019, 149, 602-612. [CrossRef]

24. Hijikata, K.; Fukasaku, Y.; Nakabeppu, O. Theoretical and experimental studies on the pseudo-dropwise condensation of a binary vapor mixture. J. Heat Transf. 1996, 118, 140-147. [CrossRef] 
25. Akiyama, H.; Nagasaki, T.; Ito, Y. Numerical analysis on the dropwise condensation of a binary vapor mixture. In The 2001 ASME International Mechanical Engineering Congress and Exposition; IMECE: New York, NY, USA, 2001; Volume 369-1, pp. 291-299.

26. Kanatani, K. Stability of a condensing liquid film in a binary vapor mixture system. Int. J. Heat Mass Transf. 2013, 58, 413-419. [CrossRef]

27. Kanatani, K. On the critical thickness and wavelength of a condensing thin liquid film in a binary vapor mixture system. Int. J. Heat Mass Transf. 2015, 80, 199-205. [CrossRef]

28. Kanatani, K.; Oron, A. Nonlinear effect of surface disturbances on mass flux and its modeling in Marangoni dropwise condensation. Int. J. Heat Mass Transf. 2016, 94, 419-425. [CrossRef]

29. Li, Y.; Yan, J.J.; Wang, J.S.; Wang, G.X. A semi-empirical model for condensation heat transfer coefficient of mixed ethanol-water vapors. J. Heat Transf. 2011, 133, 1-11. [CrossRef]

30. Sparrow, E.M.; Marschall, E. Binary, gravity-flow film condensation. J. Heat Transf. 1969, 91, $205-211$. [CrossRef]

31. Wang, J.S.; Yan, J.J.; Li, Y.; Hu, S.H.; Sunden, B. Correlation for Marangoni condensation heat transfer of water-ethanol mixture vapors. Heat Transfer Eng. 2016, 37, 774-782. [CrossRef]

32. Zhou, W.Q.; Hu, S.H.; Ma, X.R.; Zhou, F. Condensation heat transfer correlation for water-ethanol vapor mixture flowing through a plate heat exchanger. Heat Mass Transf. 2018, 54, 3025-3033. [CrossRef]

33. Fujii, T. Theory of Laminar Film Condensation; Springer: New York, NY, USA, 1991.

34. Le Fevre, E.J.; Rose, J.W. A theory of heat transfer by dropwise condensation. In Proceedings of the 3rd International Heat Transfer Conference, Chicago, IL, USA, 7-12 August 1966; pp. 362-375.

35. Rose, J.W. Dropwise condensation theory. Int. J. Heat Mass Transf. 1981, 24, 191-194. [CrossRef]

36. Graham, C.; Griffith, P. Drop size distributions and heat transfer in dropwise condensation. Int. J. Heat Mass Transf. 1973, 16, 337-346. [CrossRef]

37. Tanasawa, I.; Shibata, Y. Dropwise condensation at low heat flux and small surface subcooling. In Proceedings of the 18th National Heat Transfer Conference, San Diego, CA, USA, 6-8 August 1979; pp. 79-84.

38. Utaka, Y.; Kenmotsu, T.; Yokoyama, S. A study on Marangoni condensation (measurement and observation for water and ethanol vapor mixture). In Proceedings of the 11th International Heat Transfer Conference, Kyongju, Korea, 23-28 August 1998; pp. 397-402.

39. Utaka, Y.; Nishikawa, T. An investigation of liquid film thickness during solutal Marangoni condensation using a laser absorption method: Absorption property and examination of measuring method. Heat Transf. Asian Res. 2003, 32, 700-711. [CrossRef]

40. Utaka, Y.; Nishikawa, T. Measurement of condensate film thickness for solutal Marangoni condensation applying laser extinction method. J. Enhanc. Heat Transf. 2003, 10, 119-129. [CrossRef]

Publisher's Note: MDPI stays neutral with regard to jurisdictional claims in published maps and institutional affiliations.

(C) 2020 by the authors. Licensee MDPI, Basel, Switzerland. This article is an open access article distributed under the terms and conditions of the Creative Commons Attribution (CC BY) license (http://creativecommons.org/licenses/by/4.0/). 